\title{
Annual audit of three year outcome in very low birthweight infants
}

Mersey Regional

Neonatal Intensive

Care Unit, Liverpool

Maternity Hospital,

Liverpool L7 7BN

Correspondence to: Professor Cooke.

Accepted 4 June 1993

\begin{abstract}
Annual odds ratios, standardised for known confounding variables, were used to examine trends in outcome at 3 years of age among 1499 infants of less than $1500 \mathrm{~g}$ birth weight admitted to a regional referral centre between 1980 and 1989. Despite improved survival, the chance of survival with a major disability or with cerebral palsy was unchanged. The likelihood of dying or surviving with a major disability significantly reduced during the decade.
\end{abstract}

(Arch Dis Child 1993; 69: 295-298)

Ample evidence exists to suggest that the survival rates for very low birthweight (VLBW) infants have improved consistently since the introduction of neonatal intensive care. ${ }^{1}$ Reported rates of disabilities in the survivors have varied widely, and it is still unclear as to whether such care alters the likelihood of a preterm infant surviving with a disability. In 1979 Stewart and colleagues reviewed most of the published follow up data then available, and concluded that disability rates had remained largely unchanged over the previous 30 years, while survival had improved steadily. ${ }^{2}$ A less optimistic picture is revealed by the Mersey Regional Cerebral Palsy Register, which shows a sixfold increase in the prevalence of cerebral palsy in VLBW infants during the 1970s, although in a period antedating neonatal intensive care in this region for this weight group. ${ }^{3}$

Prospective follow up of a cohort of VLBW infants admitted to a regional neonatal intensive care unit over a 10 year period has allowed the examination of standardised trends in the risk of major disabilities at the age of 3 years and their relationship to survival rates.

\section{Patients and methods}

All infants of less than $1500 \mathrm{~g}$ birth weight admitted to the Mersey regional neonatal intensive and special care unit between 1 January 1980 and 31 December 1989 were included in the study. By using the admission registers, case records, cranial ultrasound records, and microfilmed intensive care records, the year of birth and descriptive and outcome variables were obtained for each infant (table 1). To these data, outcome data from follow up at 3 years of age was added. In the great majority of cases this was carried out on a continuing annual basis by the author and

Table 1 Definitions of variables used in analysis

\begin{tabular}{ll}
\hline $\begin{array}{l}\text { Descriptive variables } \\
\text { Birth weight } \\
\text { Gestation }\end{array}$ & $\begin{array}{l}\text { Birth weight in g } \\
\text { Gestational age in completed } \\
\text { weeks } \\
\text { Male/female } \\
\text { Yes/no } \\
\text { Vaginal/caesarean section } \\
\text { Inborn/outborn }\end{array}$ \\
$\begin{array}{l}\text { Sex } \\
\text { Multiple pregnancy } \\
\text { Place of birth }\end{array}$ & $\begin{array}{l}\text { Survival to discharge from unit } \\
\text { Outcome variables }\end{array}$ \\
$\begin{array}{l}\text { Survival } \\
\text { Parenchymal haemound scan evidence of } \\
\text { cerebral parenchymal } \\
\text { haemorrhage or infarction }\end{array}$ \\
Cerebral palsy & $\begin{array}{c}\text { Neurological impairment of } \\
\text { movement or tone. } \\
\text { Sufficient to affect daily } \\
\text { living }\end{array}$ \\
Categories 3 and 4 (table 2)
\end{tabular}

Table 2 Functional categorisation of infants at follow up at 3 years of age

(1) Normal - no clinically apparent neurodevelopmental abnormality causing functional disability

2) Mild disability - for example, myopia, language delay, mild hearing loss, hyperactivity or motor clumsiness

(3) Moderate disability - for example, spastic diplegia, hemiplegia, or moderate learning disability (developmental quotient 50-69)

(4) Severe disability - for example, spastic quadriplegia blindness, deafness (loss 70 decibels or more), uncontrolled epilepsy, or severe learning disability (developmental quotient $<50$ )

Table 3 Cross tabulation of descriptive variables with year of birth ( $\chi^{2}$ for trend) and survival by year of birth

\begin{tabular}{|c|c|c|c|c|c|c|c|c|c|c|c|c|}
\hline & 1980 & 1981 & 1982 & 1983 & 1984 & 1985 & 1986 & 1987 & 1988 & 1989 & Total & Significance \\
\hline \multicolumn{13}{|l|}{ Birth weight (g) } \\
\hline $\begin{array}{c}<750 \\
750-999 \\
1000-1249 \\
1250-1499\end{array}$ & $\begin{array}{l}13 \\
35 \\
49 \\
33\end{array}$ & $\begin{array}{l}17 \\
45 \\
51 \\
55\end{array}$ & $\begin{array}{l}12 \\
39 \\
48 \\
50\end{array}$ & $\begin{array}{l}16 \\
42 \\
61 \\
59\end{array}$ & $\begin{array}{l}13 \\
46 \\
50 \\
33\end{array}$ & $\begin{array}{l}15 \\
38 \\
53 \\
47\end{array}$ & $\begin{array}{l}23 \\
38 \\
45 \\
58\end{array}$ & $\begin{array}{l}25 \\
38 \\
50 \\
50\end{array}$ & $\begin{array}{l}11 \\
38 \\
35 \\
38\end{array}$ & $\begin{array}{l}21 \\
42 \\
37 \\
30\end{array}$ & $\begin{array}{l}166 \\
401 \\
479 \\
453\end{array}$ & $p=0.05$ \\
\hline $\begin{array}{l}\text { Gestation (weeks) } \\
22-25 \\
26-28 \\
29-31 \\
32-34 \\
\text { Inborn (\%) } \\
\text { Caesarean }\end{array}$ & $\begin{array}{l}9 \\
61 \\
40 \\
20 \\
75(58)\end{array}$ & $\begin{array}{c}12 \\
81 \\
57 \\
18 \\
103(61)\end{array}$ & $\begin{array}{l}9 \\
69 \\
47 \\
24 \\
91(61)\end{array}$ & $\begin{array}{c}22 \\
71 \\
58 \\
27 \\
128(72)\end{array}$ & $\begin{array}{c}13 \\
66 \\
49 \\
14 \\
104(73)\end{array}$ & $\begin{array}{c}24 \\
60 \\
53 \\
16 \\
106(69)\end{array}$ & $\begin{array}{l}19 \\
64 \\
67 \\
14 \\
115(70)\end{array}$ & $\begin{array}{l}27 \\
62 \\
60 \\
14 \\
107(66)\end{array}$ & $\begin{array}{l}16 \\
58 \\
33 \\
15 \\
86(71)\end{array}$ & $\begin{array}{l}24 \\
55 \\
43 \\
8 \\
85(65)\end{array}$ & $\begin{array}{l}175 \\
647 \\
507 \\
170 \\
1000(67)\end{array}$ & $\begin{array}{l}p=0.0008 \\
p=0.045\end{array}$ \\
\hline $\begin{array}{l}\text { section (\%) } \\
\text { Survived to }\end{array}$ & 37 (29) & $52(31)$ & $58(39)$ & $66(37)$ & $71(50)$ & $78(51)$ & $88(54)$ & $76(47)$ & $60(49)$ & $60(46)$ & $646(43)$ & $\mathrm{p}<0.00001$ \\
\hline $\begin{array}{l}\text { discharge (\%) } \\
\text { Survived to }\end{array}$ & $76(58)$ & $114(68)$ & $100(67)$ & $133(75)$ & $95(67)$ & $103(67)$ & $125(76)$ & $114(70)$ & $89(73)$ & $94(72)$ & $1043(70)$ & \\
\hline 3 years $(\%)$ & $71(55)$ & $112(67)$ & $96(64)$ & $128(72)$ & $93(65)$ & $99(65)$ & $120(73)$ & $113(69)$ & $79(65)$ & $92(71)$ & $1003(67)$ & \\
\hline Total & 130 & 168 & 149 & 178 & 142 & 153 & 164 & 163 & 122 & 130 & 1499 & \\
\hline
\end{tabular}


Table 4 Cross tabulation of descriptive variables and outcome variables showing probability that association is due to chance $\left(\chi^{2}\right)$

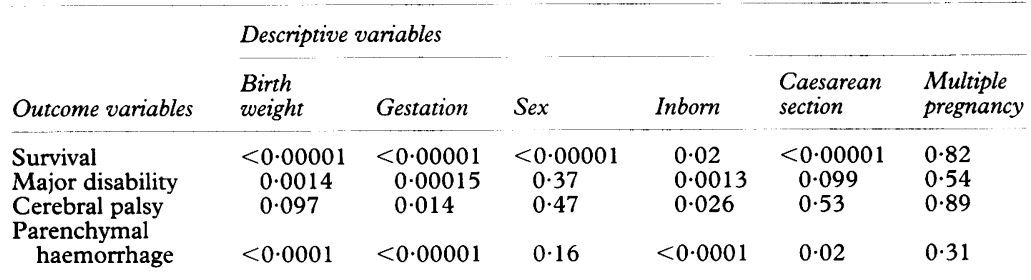

consultant colleagues at the regional centre, with referral to a child development centre in selected cases. In $15 \%$ of cases follow up data were available only from the local hospital paediatrician, a general practitioner, or health visitor. Additional information was obtained in these cases by writing to parents of infants not attending the regional centre for follow up. Infants were classified into four functional disability groups using a previously published system (table 2 ). ${ }^{4}$ Only those infants in groups 3 and 4 were considered together as 'disabled' in this study, as milder group 2 problems were often only noted at school age or later, and their diagnosis is more subjective.

Descriptive variables were cross tabulated with the year of birth to examine for changes in the nature of the patient population over the 10 year period (table 3 ). The same variables were then similarly compared with the outcome variables to see which might act as confounding variables when trends in annual prevalence of the outcomes were examined (table 4). Each outcome variable was then entered into a logistic regression analysis as the dependent variable, with each year and the identified confounding variables as the independent variables. From the analyses, the odds ratio and its $95 \%$ confidence interval for the risk of each outcome for each year compared with 1980 , and standardised for the other significantly related variables, was obtained. Further analyses were performed using death, a disability, or cerebral palsy as an independent variable to correct for the effect of improved survival and the resulting odds ratios re-examined.

The $\chi^{2}$ test and the $\chi^{2}$ test for trend were used to test for significance in the cross

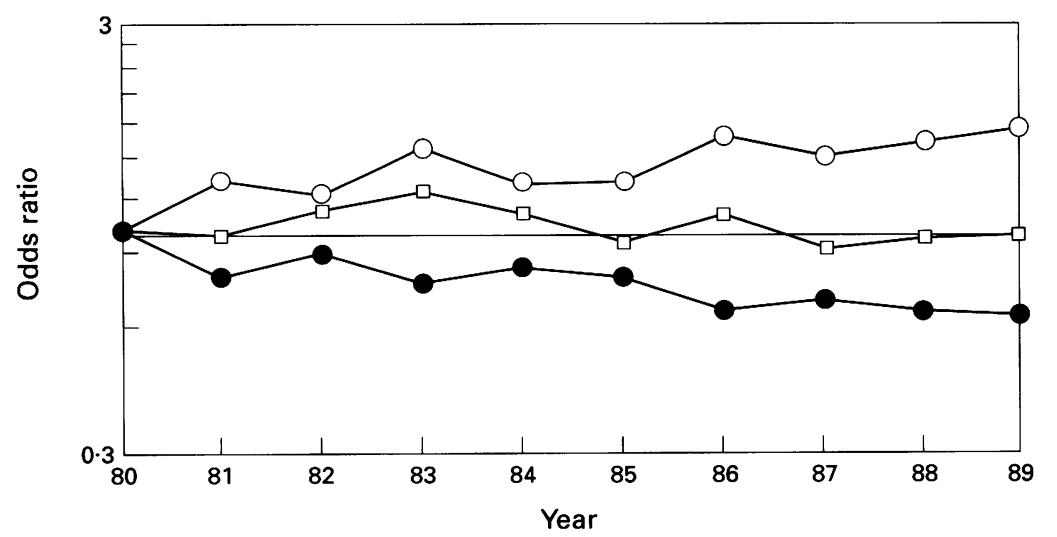

$\multimap$ Major disability $\longrightarrow$ - Survival $\multimap$ Death or disability

Figure 1 Annual standardised odds ratios for survival, disability, and death or disability, $1980-9$.
Table 5 Annual standardised odds ratios (confidence intervals) for outcomes

$\begin{array}{ll} & \text { Survival } \\ 1980 & 1 \\ 1981 & 1.32(1.01 \text { to } 1.74) \\ 1982 & 1.23(0.93 \text { to } 1.62) \\ 1983 & 1.59(1.21 \text { to } 2.11) \\ 1984 & 1.32(1.00 \text { to } 1.74) \\ 1985 & 1.32(1.00 \text { to } 1.75) \\ 1986 & 1.70(1.28 \text { to } 2.27) \\ 1987 & 1.53(1.15 \text { to } 2.03) \\ 1988 & 1.65(1.22 \text { to } 2.25) \\ 1989 & 1.80(1.33 \text { to } 2.43)\end{array}$

Disability

$0.98(0.64$ to 1.49$)$

$1.12(0.74$ to 1.70$)$

$1.25(0.86$ to 1.87$)$

$1.11(0.72$ to 1.69$)$

$0.95(0.62$ to 1.48$)$

$1 \cdot 11(0.74$ to 1.68$)$

$0.93(0.60$ to 1.44$)$

$0.98(0.62$ to 1.54$)$

$1.00(0.64$ to 1.58$)$

Parenchymal haemorrhage in survivors

Cerebral palsy

1

$0.79(0.48$ to 1.31$)$

$1.04(0.66$ to 1.66$)$

$1.05(0.67$ to 1.64$)$

$0.89(0.54$ to 1.48$)$

$0.89(0.54$ to 1.48$)$
$0.97(0.61$ to 1.57$)$

$0.97(0.61$ to 1.57$)$

$0.89(0.72$ to 1.75$)$

$0.91(0.56$ to 1.47$)$
$0.93(0.56$ to 1.55$)$

$0.93(0.56$ to 1.55$)$
$0.92(0.55$ to 1.52$)$

Death or disability

1

1 . $0.78(0.61$ to 1.01$)$

$0.78(0.61$ to 1.01$)$

$0.89(0.68$ to $1 \cdot 16)$

$0.76(0.59$ to 1.00$)$

$0.83(0.63$ to 1.08$)$
$0.79(0.60$ to 1.03$)$

$0.79(0.60$ to 1.03$)$
$0.66(0.51$ to 0.86$)$

$0.70(0.53$ to 0.91$)$

$0.66(0.50$ to 0.89$)$

$0.65(0.49$ to 0.86$)$

$1.01(0.60$ to 1.70$)$

$1.02(0.59$ to 1.75$)$

$0.82(0.47$ to 1.41$)$

$0.84(0.47$ to 1.53$)$

$1.22(0.74$ to 2.04$)$

$1.22(0.74$ to $2 \cdot 04)$

$1.15(0.70$ to 1.90$)$

$0.64(0.35$ to $1 \cdot 19)$

$0.81(0.44$ to 1.47$)$
$0.79(0.45$ to 1.41$)$

Death or cerebral palsy

$0.74(0.57$ to 0.96$)$

$0.84(0.66$ to 1.12$)$

$0.69(0.53$ to 0.90$)$

$0.69(0.53$ to 0.90$)$
$0.77(0.58$ to 1.00$)$

$0.77(0.58$ to 1.00$)$
$0.79(0.60$ to 1.03$)$

$0.66(0.51$ to 0.87$)$

$0.68(0.52$ to 0.89$)$

$0.64(0.48$ to 0.86$)$

$0.59(0.45$ to 0.79$)$

tabulations, and the logistic regression performed using the Logit option of the Probit program in SPSS-X Release 3.1.5

Infants lost to follow up were compared with those followed up, by weight, gestation, sex, place of birth, mode of delivery, multiple delivery, and the presence of seven neonatal complications such as parenchymal cerebral haemorrhage.

\section{Results}

A total of 1499 infants were included in the study. Data were complete apart from cranial ultrasound scans that were not performed in six infants dying soon after birth, and outcomes in the 22 infants lost to follow up. Of the descriptive variables, lower gestation and birth weight and increased frequency of caesarean section and inborn delivery were seen in more recent years (table 3 ). Outcomes were significantly associated with gestation, birth weight, inborn delivery, sex, and birth by caesarean section (table 4). The odds ratios for survival, major disability, and death or major disability are shown in fig 1 and table 5. The odds ratios for survival, cerebral palsy, and death or cerebral palsy are shown in fig 2 and table 5, and for survival, cerebral palsy and parenchymal haemorrhage (in survivors only) in fig 3 and table 5.

A trend to a significantly increased chance of survival compared with 1980 was seen from 1983 onwards. The odds ratios for major disability, cerebral palsy, and parenchymal cerebral haemorrhage in survivors did not differ significantly from 1 during the study period. The chance of death or major disability, and of death or cerebral palsy, both declined over the decade, and to a significant degree from 1986 onwards. 


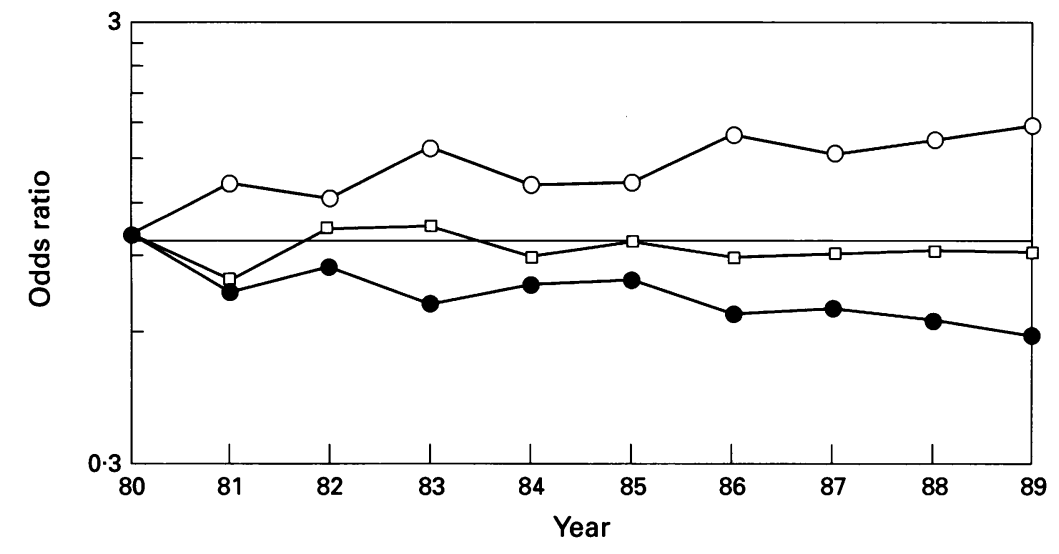

$\rightarrow-$ Cerebral palsy $\multimap-$ Survival $\rightarrow$ Death or cerebral palsy

Figure 2 Annual standardised odds ratios for survival, cerebral palsy, and death or cerebral palsy, for 1980-9.

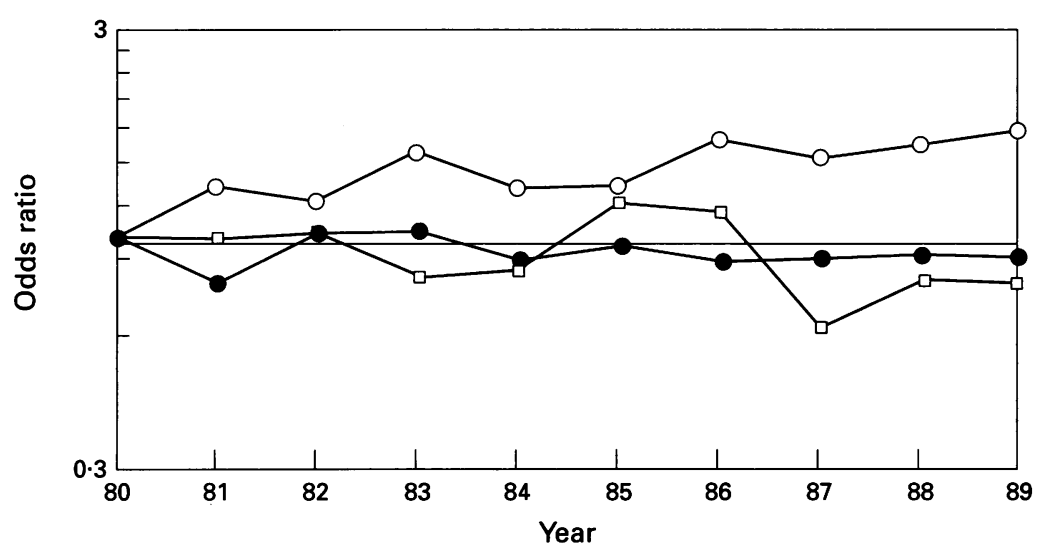
haemorrhage

Figure 3 Annual standardised odds ratios for survival, cerebral palsy, and parenchymal cerebral haemorrhage in survivors, 1980-9.

The 22 infants lost to follow up differed from the rest of the cohort only in that they had a significantly higher birth weight and gestational age.

\section{Discussion}

Despite substantial improvements in neonatal survival for VLBW infants over the past decades, the prevalence of major long term morbidity remains high. Many claims have been made with regard to the effects of intensive care on reducing this morbidity in recent years, but the evidence to support this is problematical. Studies reported are often small, use widely differing criteria for disability, patient selection and duration of follow up, making temporal comparisons difficult. A recent meta-analysis involving 111 reported studies over a 30 year period suggested that it was not possible to determine whether the rate of disability had changed or not with time. ${ }^{1}$ Escobar et al reported a median prevalence of cerebral palsy of $7 \cdot 7 \%$ and of all 'disabilities' of $25 \%$ among VLBW survivors in their metaanalysis, which compares with $10.5 \%$ and $21.4 \%$ among survivors in this cohort (tables 6 and 7). Individual centres have claimed a

Table 6 Mortality and 3 year morbidity categories for survivors, 1980-9 inclusive

\begin{tabular}{lc}
\hline & No (\%) \\
\hline & $n=1499$ \\
Died on unit (normally formed) & $424(28 \cdot 3)$ \\
Died on unit (malformation) & $32(2 \cdot 1)$ \\
Died after discharge & $40(2 \cdot 7)$ \\
Lost to follow up & $22(1 \cdot 5)$ \\
Infants followed up (outcome category $\left.{ }^{\star}\right):$ & $n=981$ \\
1. Normal & $770(78 \cdot 5)$ \\
2. Minor & $67(6 \cdot 8)$ \\
3. Moderate & $79(8 \cdot 0)$ \\
4. Severe & $65(6 \cdot 6)$ \\
\hline
\end{tabular}

${ }^{\star}$ See table 2 for definitions.

reduction in disability among VLBW survivors in more recent years. ${ }^{67}$ Even if a change in disability rate is observed in a region or centre, changes in patient selection or obstetric practice may be responsible. By expressing survival and disabilities in terms of their odds ratio compared with an index year after standardisation for confounding variables, trends over the decade may be reliably examined.

As expected, a significant trend to improved chance of survival was seen. The chance of survival with a moderate to severe disability or cerebral palsy did not differ significantly from that in 1980 over the decade. The chance of dying or surviving with a major disability or cerebral palsy declined significantly. The implication of these findings is that the application of neonatal intensive care does not increase the risk of disabled survival as has often been feared but promotes normal survival. While cerebral palsy only represents about half of the major disability recorded, it is often presumed to be largely antenatally determined at least in full term infants. If this were so in the VLBW infant, improved survival might be expected to increase the chance of surviving with cerebral palsy, but this was not so. Cerebral palsy consists of several disorders with differing antecedents, but small numbers preclude analysis by cerebral palsy type. Cerebral palsy is strongly associated in VLBW infants with cerebral parenchymal haemorrhage and infarction. ${ }^{8}$ The odds ratio for parenchymal haemorrhage among survivors did not change over the decade, and so it is perhaps not surprising that cerebral palsy odds also remained unchanged.

Types of disability other than cerebral palsy are listed in table 7 , but did not occur frequently enough to allow individual analysis of trend with time. There is no reason to believe that different disabilities have the same cause, and so their analysis together may not be justified, and may conceal real changes in some.

Weaknesses of this study are in common with many others. The staff examining the children were aware of their past medical histories, but the outcomes observed as disabilities were reasonably robust and objective. Some $15 \%$ of infants were not seen at 3 years at the perinatal centre, but it was felt more important to include data from other health professionals rather than exclude them. Twenty two infants were lost to follow up. While it is impossible to be certain that these infants did not differ markedly in outcome from the infants 
Table 7 Survivors followed up with major disability (categories 3 and 4) $(n=981)$

\begin{tabular}{lr} 
& No (\%) \\
\hline Cerebral palsy & \\
Spastic diplegia & $34(3 \cdot 5)$ \\
Spastic hemiplegia & $38(3 \cdot 9)$ \\
Spastic bilateral hemiplegia & $28(2 \cdot 9)$ \\
Other & $3(0 \cdot 3)$ \\
Total & $103(10 \cdot 5)$ \\
Cognitive delay & \\
$\quad$ Moderate (DQ 50-70) & $45(4 \cdot 6)$ \\
Severe (DQ <50) & $20(2 \cdot 0)$ \\
Named syndromes with cognitive delay & $4(0 \cdot 4)$ \\
Deafness (severe sensorineural) & $13(1 \cdot 3)$ \\
Visual impairment (cortical blindness and & \\
$\quad$ retinopathy of prematurity) & $17(1 \cdot 7)$ \\
Severe & $18(1 \cdot 8)$ \\
Blind & \\
Convulsions (non-febrile) after discharge & $18(1 \cdot 8)$ \\
from unit & $54(5 \cdot 5)$
\end{tabular}

Infants may appear in more than one disability group.

$\mathrm{DQ}=$ developmental quotient.

followed up, they were very similar when compared on known perinatal variables.

The study, while including about $60 \%$ of the VLBW infants estimated to have been born in the centre's referral area over the decade, was not of a geographically defined group. Standardisation for variation with time of gestation, birth weight, referral pattern, and caesarean section rates may have gone some way to correct for the biases introduced by a hospital centred study. On the positive side, a single centre study allows for some degree of uniformity of factors such as cranial ultrasound interpretation, medical management, and categorisation of disabilities; and on the question of size, with 1499 infants, the study compares favourably with the 1408 infants from 21 studies from 1980 reviewed by Escobar et al . ${ }^{1}$

While standardised follow up of intensive care survivors on a regional or national basis is the ideal, until this is achieved, larger referral centres could use the methods described here to reduce biases in monitored outcomes. Although no clear trends to reduction in morbidities have been demonstrated in this study period, the very recent widespread adoption of exogenous surfactant treatment and increased use of antenatal steroids may produce such effects in the present decade.

I thank Dr A M Weindling for his help in following up many of the children, and the very many paediatricians, family doctors, health visitors, and parents in the Mersey region, elsewhere in the UK, and abroad who have willingly supplied information about the children who could not return to Liverpool.

1 Escobar GJ, Littenberg B, Petitti DB. Outcome among surviving very low birthweight infants: a meta-analysis. Arch Dis Child 1991; 66: 204-11.

2 Stewart AL, Reynolds EOR, Lipscomb APL. Outcome for infants of very low birthweight: survey of world literature. Lancet 1981; i: 1038-41.

3 Pharoah POD, Cooke T, Cooke RWI, Rosenbloom L. Birthweight specific trends in cerebral palsy. Arch Dis Child 1990; 65: 602-6.

4 Pharoah POD. Stevenson RC, Cooke RWI, Sandhu B. Costs and benefits of neonatal intensive care. Arch Dis Child 1988; 63: 715-8.

5 SPSS Inc. SPSS-X users guide. 3rd Ed. Chicago: SPSS Inc, 1988

6 The Victoria Infant Collaborative Study Group. Improvement of outcome for infants of birth weight under 1000 g. Arch Dis Child 1991; 66: 765-9.

7 Saigal S, Rosenbaum P, Hattersley B, Milner R. Decreased disability rate among 3 year old survivors weighing 501-1000 grams at birth and born to residents of a geographically defined region from 1981-1984 compared geographically defined region from 1981-1984
with 1977 to 1980 . $\mathcal{F}$ Pediatr $1989 ; 114: 836-46$.

8 Cooke RWI. Cerebral palsy in very low birthweight infants. Arch Dis Child 1990; 65: 201-6. 